\title{
A VIOLENCIA CONTRA O IDOSO NA VISÃO DO AGENTE COMUNITÁRIO DE SAÚDE
}

\author{
Diane Sousa Sales ${ }^{1}$ \\ Cibelly Aliny Freitas ${ }^{2}$ \\ Maria da Conceição Brito ${ }^{3}$ \\ Eliany Oliveira ${ }^{4}$ \\ Fernando Dias ${ }^{5}$ \\ Fabiara Parente ${ }^{6}$ \\ Maria Josefina Silva
}

1 Discente do Curso de Mestrado em Saúde Coletiva pela Universidade de Fortaleza. Enfermeira assistencialista do Hospital Universitário Walter Cantídio. E-mail: diane-enf@hotmail.com

2 Doutora em Enfermagem pela Universidade Federal do Ceará (UFC). Docente do Curso de Enfermagem da Universidade Estadual do Vale do Acaraú. E-mail: cibellyaliny@gmail.com

3 Discente do Curso de Mestrado em Saúde da Família pela Universidade Federal do Ceará (UFC). Docente do Curso de Enfermagem da Universidade Estadual do Vale do Acaraú. E-mail: marycey@ hotmail.com

4 Doutora em Enfermagem pela Universidade Federal do Ceará (UFC). Docente do Curso de Enfermagem da Universidade Estadual do Vale do Acaraú. E-mail: elianyy@hotmail.com

5 Sociólogo. Coordenador do Núcleo de Prevenção das Violências e Promoção da Saúde de Sobral (NPVPS)/Escola de Formação em Saúde da Família Visconde de Sabóia - Núcleo de Estudos e Pesquisas em Saúde (NEPS). E-mail: fcavalcantedias@yahoo.com.br

6 Bacharel em Enfermagem pela Universidade Estadual do Vale do Acaraú. Enfermeira do Hospital do Coração de Sobral/CE. E-mail: fabiaraparente@hotmail.com

7 Doutora em Enfermagem pela UFC. Coordenadora de Enfermagem da Universidade Federal do Ceará. E-mail: mjosefina@terra.com.br 
resumo

Identificar a percepção do agente comunitário de saúde (ACS) em relação ao idoso que foi vítima de violência e analisar o fluxo de atendimento dos casos de violência contra o idoso identificados pelos ACS. Trata-se de estudo exploratório e descritivo com uma abordagem qualitativa, sendo os sujeitos os ACS. A coleta de informações foi realizada por meio de entrevista semiestruturada e os dados foram categorizados com base no referencial de análise temática de Minayo. Os aspectos da Resolução n. 196/96 do Conselho Nacional de Saúde (CNS) foram observados. Neste estudo, a partir das falas dos ACS, surgiram duas categorias: 1) Percepção sobre o idoso identificado como vítima de violência, na qual se retrata a imagem da violência observada durante as visitas domiciliares; e 2) Notificação: identificação do caso no fluxo de atendimento - esta aponta que as instituições que notificam e acolhem o idoso que foi vítima de violência são as unidades básicas de saúde (UBS) e o Centro de Referência de Assistência Social (CRAS). A partir dessas instituições, ocorre o encaminhamento para outros serviços. Conclui-se que os ACS consideram a violência intrafamiliar predominante, que é cometida por quem compartilha o dia a dia com o idoso e envolve, principalmente, a negligência. Em relação às instituições, estas não dialogam na perspectiva de socialização de informações dos casos notificados, assim, vivencia-se uma ausência de fluxo de atendimento para essa família. Em compensação, os ACS apresentam uma proposta de fluxo de atendimento para as instituições.

palavras-chave

Maus-tratos ao Idoso. Notificação. Agentes Comunitários de Saúde.

A violência contra o idoso é considerada um problema de saúde pública; representa, segundo o National Center on Elder Abuse (2013), o abuso físico, sexual, emocional e/ou psicológico e inclui a negligência e a exploração financeira. A violência contra o idoso promove impactos negativos sobre a saúde da vítima, como altas taxas de morbidade e mortalidade, aumento do risco de lesão e uma série de problemas de saúde e doenças crônicas. 
Nesse contexto, adentra-se o âmbito da violência contra o idoso como uma temática que vem sendo discutida recentemente na sociedade; porém, ela é observada desde tempos remotos. Com o aumento do crescimento populacional da terceira idade e da expectativa de vida, ocasionado pela melhoria do padrão de vida com a evolução da medicina, dos medicamentos e dos tratamentos, tornaram-se mais evidentes os problemas enfrentados por essa faixa etária, dentre eles a violência.

Em estudo realizado com notificações em 2009, constatou-se que as causas externas, como acidentes e violência, ocuparam a sexta posição entre os óbitos de idosos no Brasil, correspondendo, assim, a um risco de morte por homicídio de 9,9 idosos por 100 mil idosos (MASCARENHAS et al., 2011).

Observa-se que os estudos sobre a violência nas cidades brasileiras tornam-se cada vez mais presentes nas publicações especializadas, além de a violência ser tema de registro cotidiano na mídia, na pauta de preocupação de políticos e intelectuais e no pensamento da população, que se vê cada vez mais insegura onde quer que seja, até mesmo em casa, local em que se espera haver proteção e segurança. É comum a afirmação de que a violência faz parte do cotidiano; ela está presente no trânsito, no trabalho, nas ruas, nas escolas, nos lares (D'ALENCAR, 2005).

O campo de estudo da violência se depara constantemente com as ambiguidades decorrentes desse fenômeno, pois adquire múltiplas significações quando analisado sob a perspectiva das relações interpessoais. A violência extrema é facilmente reconhecida e condenada, porém, quando se expressa de forma sutil, tende a permanecer na invisibilidade; quando o agressor é uma pessoa desconhecida ou distante, o ato é mais facilmente reconhecido do que quando quem o pratica é uma pessoa com a qual se tem relações próximas. Nesse sentido, compreende-se que a violência faz parte da ambivalência humana, na medida em que todas as pessoas trazem em si o potencial para amar e odiar, construir e destruir; dosar sentimentos, ações e limites é um desafio constante nas relações interpessoais (WANDERBROOCKE; MORE, 2012).

Na maioria dos casos, a violência contra o idoso ocorre no meio intrafamiliar e o agressor é alguém que cuida do idoso ou possuí vínculo, onde se destacam o filho, a nora e os netos. Florêncio et al. (2007) afirmam que a convivência dos idosos com indivíduos mais jovens e a dependência obrigatória pode gerar conflitos, a ponto de a relação entre eles tornar-se insustentável.

Esses conflitos podem gerar vários tipos de violência, como dano intencional físico, moral, psicológico e/ou social, ou seja, o resultado de atos (ou 
omissões) da família ou responsável, que violam os padrões da comunidade no que diz respeito aos idosos (OLIVEIRA et al., 2012).

Por causa desses vínculos, a maior parte das denúncias é realizada por terceiros, já que os idosos, em geral, não têm coragem de denunciar, por motivos de afetividade e parentesco com os agressores e, além disso, essas vítimas têm sentimentos de inutilidade e dependência, assim, acreditam que necessitam submeter-se a situações desse tipo até o momento da morte.

Enfatiza-se o papel do profissional de saúde nesse contexto, já que a violência contra a pessoa idosa, muitas vezes, passa despercebida por esses profissionais. Para a detecção da violência é indispensável a prontidão e a atenção para identificar os sinais de alerta. A questão da violência envolve não só o idoso vitimado, mas sua família, os profissionais que cuidam dele e, em uma perspectiva um pouco mais distante, o sistema de saúde, que tratará desse idoso e das consequências dessa situação (SANCHES et al., 2008).

A Lei n. 12.461/2011 (BRASIL, 2011) estabeleceu que os casos de suspeita ou confirmação de violência cometida contra idosos são de notificação compulsória pelos serviços de saúde públicos e privados à autoridade sanitária e, também, comunicados aos seguintes serviços: autoridade policial; Ministério Público; Conselho Municipal do Idoso; Conselho Estadual do Idoso e Conselho Nacional do Idoso.

As autoras Wanderbroocke e More (2012) afirmam que, no Brasil, apesar dos avanços obtidos nas políticas públicas voltadas ao enfrentamento da violência contra os idosos, estas ainda não foram implementadas em sua totalidade. O contexto da atenção primária à saúde tem especial importância nesse processo, pois possibilita um acesso privilegiado à população e proporciona aos profissionais de saúde a possibilidade de atuar na promoção de saúde e no encaminhamento dos agravos detectados. Entretanto, lidar com situações que envolvem violência contra o idoso exige preparo profissional, pois as autoras mostram que os idosos vitimados pela família vivem em isolamento e encontram dificuldade para revelar os abusos sofridos, por vergonha ou medo de retaliação dos agressores.

Assim, é importante contar com uma equipe multiprofissional para contribuir na identificação e confirmação da violência, pois se analisa a situação no aspecto social, médico e psicológico e podem-se traçar intervenções legais e adequadas ao caso. Nesse contexto, o agente comunitário de saúde (ACS), a partir de sua visita, com atuação importante na equipe de saúde da família, proporciona um vínculo contínuo com a clientela da área abrangida por sua unidade (CARDOSO et al., 2011). 
Avaliando as publicações científicas que têm por objeto a violência contra o idoso, Espindola e Blay (2007) relatam que as publicações sobre esse tema ainda são incipientes, principalmente no Brasil, e que a violência contra a criança, o adolescente e a mulher são assuntos mais pesquisados em comparação à violência contra o idoso. Assim, objetiva-se identificar a percepção do ACS sobre o idoso vítima de violência e analisar o fluxo de atendimento dos casos de violência contra o idoso identificados pelos ACS.

\section{Métodos}

Este é um estudo exploratório e descritivo com abordagem qualitativa que teve como sujeitos ACS que atuam na Estratégia de Saúde da Família (ESF) em Sobral-CE. A coleta das informações foi realizada em abril e maio de 2010.

O ACS tem funções básicas, tais como: identificar sinais e situações de risco, orientar as famílias e a comunidade e encaminhar/comunicar à equipe os casos e situações identificadas (CARDOSO et al., 2011). Com isso, observou-se que seu conhecimento sobre violência teria impacto sobre as notificações. Além disso, as UBS de Sobral foram divididas em macrorregiões de acordo com a posição geográfica para a formação das Comissões Locais de Promoção da Cultura de Paz na Família, exposto na minuta de alteração da Portaria n. 06/2005. Escolhemos de forma aleatória trabalhar com a Macrorregião III, formada pelos bairros Sumaré e Padre Palhano.

Os critérios de inclusão dos sujeitos foram os ACS que compõem a comissão e somente aqueles que formalizaram sua anuência por meio do termo de consentimento livre e esclarecido. Com isso, cinco ACS constituíram o total de sujeitos. A coleta de informações deu-se a partir de entrevista semiestruturada, com a seguinte pergunta norteadora: "Há casos de violência contra o idoso na sua área e como você os identifica?".

As informações foram categorizadas de acordo com o objetivo proposto por meio do referencial de análise temática de Minayo (2008), que aborda como a descoberta de núcleos de sentido, evidenciados a partir dos temas que compõem uma comunicação, apresenta significado para o objetivo analítico do estudo. Posteriormente, as informações foram confrontadas com a literatura pertinente.

A operacionalização da análise temática abrange três etapas: 1) Pré-análise: são determinadas nessa fase as unidades de registro - palavras-chave ou 
frases, unidades de contexto, recortes, forma de categorização, modalidade de codificação e conceitos mais gerais que orientarão a análise; 2) Exploração do material: consiste essencialmente em uma operação classificatória que objetiva alcançar o núcleo de compreensão do texto; 3) Tratamento dos resultados obtidos: o analista propõe inferências, interpreta e inter-relaciona-as com o quadro teórico desenhado inicialmente (MINAYO, 2008).

A limitação do estudo deu-se em razão de duas agentes comunitárias serem novas na função e na participação das Comissões Locais de Promoção da Cultura de Paz na Família, fato que demandou um aumento do tempo da entrevista para que elas compreendessem as perguntas em seu contexto de trabalho.

O estudo foi aprovado pelo Comitê de Ética em Pesquisa da Universidade Estadual Vale do Acaraú (UVA), por meio do CAAE n. 0320.0.000.039-10.

\section{Resultados e discussão}

Todos os sujeitos do estudo eram do sexo feminino, com idade de 20 a 53 anos, sendo 2 casadas e 3 solteiras. Todas as mulheres tinham Ensino Médio completo e o tempo de trabalho como ACS variou de 1 ano e 4 meses a 10 anos. Essas ACS acompanhavam entre 135 e 165 famílias das UBS dos bairros Sumaré e Padre Palhano na cidade de Sobral.

As informações coletadas foram transcritas e analisadas segundo similaridade de conteúdo. Logo, surgiram duas categorias: Percepção sobre o idoso identificado como vítima de violência; e Notificação: identificação do caso no fluxo de atendimento.

\subsection{Percepção sobre o idoso identificado como vítima de violência}

A OMS (2002, p. 126) define violência contra o idoso como um:

\footnotetext{
Ato de acometimento ou omissão, que pode ser tanto intencional como involuntário. O abuso pode ser de natureza física ou psicológica ou pode envolver maus-tratos de ordem financeira ou material. Qualquer que seja o tipo de abuso, certamente resultará em sofrimento desnecessário, lesão ou dor, perda ou violação dos direitos humanos e uma redução na qualidade de vida do idoso.
} 
Segundo Sanches et al. (2008), esse conceito também foi detalhado pela instituição Action on Elder Abuse, no Reino Unido, e adotada pela International Network for the Prevention of Elder Abuse (Inpea) em 2002.

Constata-se a convergência entre a definição da OMS e a fala da ACS que apresenta sua visão da realidade vivenciada:

A violência não só física, mas a violência do direito de você ser cuidado até o final. As pessoas não querem mais cuidar de seus idosos. Quando a pessoa chega a uma certa idade, eles não querem ter mais responsabilidade, não querem ter mais nenhum tipo de compromisso em relação à saúde; da alimentação a tudo que eles precisam para ser acompanhados para ter uma vida melhor, eles não têm. (ACS 03)

Percebe-se na fala o que afirma D'Alencar (2005), que a desvalorização do idoso e o crescente afrouxamento dos laços solidários entre os familiares são fatores que podem contribuir para a violência contra o idoso.

A natureza dos tipos de violência que a população idosa sofre coincide com a violência social que a sociedade brasileira vivencia e produz em suas relações, e introjeta em sua cultura. Os maus-tratos ao idoso constituem um ato, sendo este único ou repetido, ou omissão que cause dano ou aflição e que ocorra em qualquer relação na qual haja expectativa de confiança (BRASIL, 2005), aspectos mencionados nas falas a seguir:

A violência não é só de bater, existe a de maus-tratos e a verbal, que é a mais presente. (ACS 04)

Eu acho que é o abandono ou, então, a pessoa é idosa e a família não cuida. Os familiares deixam eles em redes e nas camas e não passeiam. (ACS 05)

Em um estudo realizado na cidade de Fortaleza, Nogueira, Freitas e Almeida (2011), com as denúncias de violência contra idosos registradas pelo "Alô Idoso", apresentam os seguintes resultados: o tipo de violência mais frequente nos relatos é o psicológico, seguido de negligência, violência econômica e física. Quando enquadrada na categoria "outros", ela se refere aos casos de abandono, cárcere privado e autonegligência. Nas denúncias ao "Alô Idoso", observou-se que 66,5\% dos idosos são vítimas de mais de um tipo de violência, que são, em ordem decrescente: negligência e violência econômica; violências física e psicológica; violência psicológica e negligência; violências psicológica e econômica.

Nota-se nos discursos a definição da negligência como uma forma de violência. 
A negligência é descrita como a incapacidade de cumprir uma obrigação de cuidados e pode ser classificada como: 1) negligência intencional, na qual há completa falta de prestação de cuidados; e 2) negligência não intencional, na qual não há completa falta de prestação de cuidados ou autonegligência, ou seja, a conduta que ameaça a própria segurança do indivíduo (WAGENAAR et al., 2010).

Fonseca e Gonçalves (2003) revelam que a maioria dos casos de violência praticada contra os idosos ocorre no ambiente familiar e que seus autores são, em geral, filhos e netos das vítimas, mas, também, amigos, inquilinos e senhorios.

Nesse contexto, entende-se como violência intrafamiliar aquela que se refere às relações pessoais e ocorre no âmbito doméstico, no interior do lar, e ela tem-se feito presente na maioria dos casos de violência contra o idoso. Muller (2008) explica que a violência intrafamiliar e doméstica ocorre nas relações interpessoais nas quais, simultaneamente, a cumplicidade e o medo se impõem pelo autoritarismo do agressor ou pelo imaginário e simbolismo da confiança entre vítima e agressor. Essa afirmativa pode ser observada na fala de um ACS:

\section{É a pessoa que vive com ele, é quem compartilha o dia a dia. (ACS 05)}

Mascarenhas et al. (2011) comprova essa afirmação em seu estudo sobre violência contra o idoso a partir das fichas de notificação do ano de 2010, no qual descreve que a maioria dos eventos de violência contra idosos foi causada por agressores do sexo masculino e esses, em sua maioria, eram: filhos $(32,2 \%)$, pessoas desconhecidas $(15,6 \%)$, parceiros conjugais $(13,9 \%)$ e outras pessoas conhecidas pela vítima $(11,8 \%)$.

\subsection{Notificação: identificação do caso}

no fluxo de atendimento

Os registros nos sistemas de informação do Brasil mostram que, em 2008, 20.303 idosos morreram por causas externas, sendo que os acidentes e a violência representam a sétima causa de óbitos nessa faixa etária; em 2009, as causas violentas perfizeram $6 \%$ das hospitalizações de idosos no país (DATASUS, 2010). 
Esses são os dados registrados, porém, como em todo caso de violência doméstica, apenas uma pequena fração dos eventos é notificada aos órgãos responsáveis, muitas vezes em função da gravidade do evento (DUMARA, 2007).

Na atenção básica, a unidade de saúde da família (USF) tem importante papel no reconhecimento desse problema, isto é, a violência intrafamiliar contra o idoso, pois possibilita à equipe maior aproximação com as questões que envolvem a violência (SHIMBO; LABRONICI; MANTOVANI, 2011).

No estudo, constatou-se que os ACS identificavam os casos de violência por meio do vínculo com a comunidade. O principal instrumento de trabalho do ACS é a visita domiciliar, utilizando abordagens diretas na promoção e prevenção da saúde. Além disso, visualiza-se importância do vínculo do ACS com as famílias, pois, em algumas situações, a informação parte dos vizinhos que identificam e denunciam a violência.

Quando acontece, sim, quando faz a visita, a gente tem contato não só com o idoso, mas também com as pessoas próximas, às vezes, um vizinho. (ACS 03)

Shimbo, Labronici e Mantovani (2011), em estudo sobre a identificação da violência contra o idoso, afirmam que ela pode ocorrer por meio da visita domiciliar, estratégia mencionada por $42 \%$ dos entrevistados, que vai ao encontro das propostas das políticas de saúde do idoso e das diretrizes de promoção do envelhecimento ativo e saudável, da atenção integral e promotora da saúde na terceira idade.

Assim, cabe aos ACS repassar o caso, registrando suas impressões e comunicando-se com os profissionais da ESF.

Quando a gente presencia e tem o conhecimento, repassa para o enfermeiro. Sempre é a gente que relata, pois o agente de saúde é o primeiro a saber. (ACS 05)

Porém, percebeu-se a dúvida dos sujeitos, uma vez que, muitas vezes, não sabiam a quem se reportar e encaminharam o caso para a enfermeira da unidade ou mesmo para a assistente social. Eles caracterizam o primeiro passo, de acolhimento, como as visitas realizadas pelos profissionais da unidade de saúde e do Centro de Referência da Assistência Social.

É feita a notificação no PSF e este encaminha para o órgão da rede responsável, penso eu, para o CRAS e o Conselho do ldoso. (ACS 05) 
A gente sempre leva a assistente social e passa também para CRAS e este fica responsável para passar para o CREAS, quando é alguma coisa mais além. Quando é uma violência que a gente possa conversar, a assistente social já tenta fazer isso. Só não obtemos respostas. (ACS 02)

A notificação da violência é de suma importância para acompanhar os casos, sendo que a Portaria n. 104, de 25 de janeiro de 2011, incluiu na relação de doenças, agravos e eventos em saúde pública de notificação compulsória em todo o território nacional a violência doméstica, sexual e/ou outras violências; estabeleceu, ainda, um fluxo e os critérios, além das responsabilidades e atribuições dos profissionais e serviços de saúde.

Apesar disso, pesquisas apontam dentre as razões para a subnotificação a dificuldade de denúncia da violência doméstica contra os idosos, o despreparo dos profissionais de saúde para investigar os casos (falta de capacitação e conhecimento de protocolos de investigação), a infraestrutura deficiente de atendimento e a fragilidade das redes de apoio (MASCARENHAS et al., 2011).

Além disso, Muller (2008) explica que a violência intrafamiliar e doméstica ocorre nas relações interpessoais onde existem, simultaneamente, uma cumplicidade e um medo que se impõem pelo autoritarismo do agressor ou pelo imaginário e simbolismo de uma confiança entre vítima e agressor. Nesse contexto, a vítima de violência continua convivendo com o agressor e um dos inúmeros motivos para tanto é o não conhecimento do procedimento de encaminhamento para instituições de abrigo, combinado ao medo de denunciar.

\section{Não, eles nunca vão para outro órgão. (ACS 02)}

Continuam em casa; aqui em nosso bairro, todo o tipo de violência contra a mulher, o idoso, normalmente fica em casa, pois não têm coragem de denunciar. (ACS 05)

Dumara (2007) indica que o medo do idoso para denunciar a violência doméstica está relacionado ao fator "perda dos laços afetivos com a família". Pode-se dizer que a resistência à violência doméstica de $91,8 \%$ dos entrevistados no estudo ultrapassa os limites do suportável. Eles contam suas histórias de angústia com riqueza de detalhes, porém, dirigir-se a um distrito policial para denunciar um ato delituoso de sua própria prole é algo que lhes causa uma dor maior que as agressões físicas, psicológicas e econômicas e a negligência sofrida no dia a dia.

A atenção às famílias e à comunidade é o objetivo central da visita domiciliar, sendo estas entendidas como instituições influenciadoras no 
processo de adoecer dos indivíduos. A análise do contexto de vida dos usuários dos serviços de saúde e de suas relações familiares deve visar ao impacto nas formas de atuação dos profissionais, possibilitando novas demarcações conceituais e, consequentemente, o planejamento das ações (ALBUQUERQUE; BOSI, 2009).

\footnotetext{
agente de saúde e o enfermeiro fazem a visita, agora mesmo a gente leva a assistente social, psicólogo até lá para conversar com a família, mas, infelizmente, a mãe não quer que ninguém faça nada contra o filho, o agressor, aí, fica difícil! (ACS 01)
}

Faz a visita e o encaminhamento para o Conselho do ldoso e pede para o agente acompanhar e identificar os acontecimentos. (ACS 04)

As visitas domiciliares também são realizadas por outros profissionais, e elas revelam a necessidade de apoio multiprofissional e interdisciplinar, tanto para o profissional de enfermagem como para a vítima. Intervir em situações de violência sempre envolve transtornos físicos, sociais e mentais. Contudo, a abordagem em equipe sempre deverá estar presente nas ações da atenção primária, pois a integralidade é um dos objetivos da assistência que norteiam os princípios do Sistema Único de Saúde (SUS).

No momento, quando indagados sobre os procedimentos realizados após a notificação da violência, constata-se que não há um fluxo de atendimento, pois, quando ocorrem os encaminhamentos, as instituições não proporcionam um retorno ao serviço, um parecer sobre a situação do caso.

Ainda muito lento, deixa muito a desejar. Não existe retorno. (ACS 01)

Não ocorre, ou, quando ocorre, não temos resposta. (ACS 02)

A Lei n. 12.461/2011 estabelece em seu artigo 19 que os casos de suspeita ou confirmação de violência contra idosos devem ser notificados e encaminhados para os seguintes órgãos: autoridade policial; Ministério Público; Conselho Municipal do Idoso; Conselho Estadual do Idoso e/ou Conselho Nacional do Idoso. Porém, nessa proposta, não há retorno aos serviços de saúde e aos profissionais da saúde que almejam a melhoria da qualidade de vida desse idoso. A fala a seguir envolve a proposta de um fluxo de atendimento.

fluxo tem que passar mesmo pelo PSF, pelo agente de saúde, pelo enfermeiro e dele para as instituições, para elas fornecerem ajuda. $\bigcirc$ trabalho em parceria é muito edificante. (ACS 04) 
De acordo com os relatos, deve-se trabalhar um fluxo de atendimento que sempre apresente o retorno para a UBS. Observando que o fluxo deve iniciar por alguém que identifique os casos, não se pode remeter apenas ao ACS, apesar de este membro das equipes de saúde da família ser um dos elos entre as necessidades de saúde da população e o que pode ser feito para melhorar suas condições de vida; ele é a ponte entre a população e os profissionais e serviços de saúde (IMPERATORI; LOPES, 2009). Deve-se ter em vista que a identificação dos casos de violência é uma função de todos os profissionais da saúde que atuam na comunidade.

\section{Considerações finais}

Conclui-se que os ACS consideram a violência intrafamiliar predominante, sendo cometida por quem compartilha o dia a dia com o idoso e apresenta-se, principalmente, por meio da negligência. Além disso, identificou-se que as instituições de notificação e acolhimento do idoso vítima de violência são as UBS e o CRAS. A partir delas ocorre o encaminhamento para outros serviços. Uma das dificuldades é a subnotificação dos casos, pois as instituições os conhecem, porém o idoso recusa-se a denunciar.

Também se observa que as instituições não dialogam sob a perspectiva de socialização de informações dos casos notificados, assim, perde-se um vínculo importante tanto com a instituição como com os atores, agressor e vítima, do caso.

Foi detectada a necessidade da criação e efetivação do fluxo de notificação, acolhimento e acompanhamento desses casos de violência e constatou-se, devido ao seu conhecimento relativo aos casos de violência em sua área de atuação, que os ACS são peças fundamentais para a formação desse fluxo. Scaranto (2007) revela que o ACS, junto com sua equipe, pode aumentar os esforços de prevenção da causa, ajudar a compreender o problema e servir de guia para o desenvolvimento de políticas públicas consistentes para as intervenções em relação ao fenômeno da violência.

Nesse contexto, uma das propostas do estudo é o fluxo de atendimento, que se inicia pela identificação e comunicação da UBS na figura de um dos profissionais como referência, com o intuito de facilitar o fluxo; posteriormente, há a comunicação com serviços como o CRAS ou o CREAS, de acordo com a infraestrutura da cidade, e estes devem proporcionar um retorno dos encaminhamentos aos profissionais da UBS e solicitar ajuda, quando necessário. 
abstract

Identify the perception of community health workers (CHWs) with regard to the elderly person victimized by violence and analyze the flow of care for cases of violence against the elderly person identified by CHWs. This is an exploratory and descriptive study with a qualitative approach, and the CHWs are its subjects. The collection of information was conducted through a semi-structured interview and the data were categorized having Minayo's thematic analysis framework as a basis. One observed the aspects of the Resolution 196/96, from the Brazilian National Health Council (CNS). In this study, through the CHWs' speeches, two categories emerged: 1) Perception on the elderly person identified as a victim of violence, in which one portrays the violence image observed during the home visits; and 2) Notification: identification of the case in the flow of care - this points out that the institutions which notify and embrace the elderly person victimized by violence are the basic health units $(\mathrm{BHU})$ and the Reference Center for Social Assistance (RCSA). Through these institutions takes place the referral to other services. One concludes that the CHWs regard the intrafamily violence as the predominant one, which is committed by someone who shares her/his daily life with the elderly person and it involves, especially, negligence. Regarding the institutions, they don't dialogue from the perspective of socializing information on the notified cases, thus, one experiences a lack of flow of care for this family. In return, the CHWs present a proposal for flow of care to the institutions.

keywords

Elder Abuse. Notification. Community Health Workers. 
ALBUQUERQUE, Adriana Bezerra Brasil de; BOSI, Maria Lúcia Magalhães. Visita domiciliar no âmbito da Estratégia Saúde da Família: percepções de usuários no Município de Fortaleza, Ceará, Brasil. Cadernos de Saúde Pública, Rio de Janeiro, v. 25, n. 5, p. 1103-1112, maio 2009

BRASIL. Plano de Ação para o Enfrentamento da Violência Contra a Pessoa Idosa. Brasília, DF: Subsecretaria de Direitos Humanos, 2005.

Lei n. 12.461, de 26 de julho de 2011. Altera a Lei n. 10.741, de $1^{\circ}$ de outubro de 2003, para estabelecer a notificação compulsória dos atos de violência praticados contra o idoso atendido em serviço de saúde. Diário Oficial da União, Brasília, 27 jul. 2011. Disponível em: <http://www.planalto.gov.br/CCIVIL_03/_Ato2011-2014/2011/ Lei/L12461.htm>. Acesso em: 11 maio 2013.

CARDOSO, Fátima Aparecida et al. Capacitação de agentes comunitários de saúde: experiência de ensino e prática com alunos de Enfermagem. Revista Brasileira de Enfermagem, Brasilia, v. 64, n. 5, p. 968-973, set./out. 2011.

D'ALENCAR, Raimunda Silva. Punidos por envelhecer. Estudos Interdisciplinares sobre o Envelhecimento, Porto Alegre, v. 8, p. 67-81, 2005.

DATASUS. Sistema de Informações Hospitalares do SUS. Brasília, DF: Ministério da Saúde, 2010.

DUMARA, Nádia. A violência contra o idoso. São Paulo: PUC-SP, 2007. Não publicado.

ESPINDOLA, Cybele Ribeiro; BLAY, Sérgio Luís. Prevalência de maus-tratos na terceira idade: revisão sistemática. Revista de Saúde Pública, São Paulo, v. 41, n. 2, p. 301-306, abr. 2007.

FLORÊNCIO, Marcía Virgínia di Lorenzo et al. A violência contra o idoso: dimensão ética e política de uma problemática em ascensão. Revista Eletrônica de Enfermagem, Goiânia, v. 9, n. 3, p. 847-857, set./dez. 2007.

FONSECA, Maria Mesquita; GONÇALVES, Hebe Signorini. Violência contra o idoso: suportes legais para a intervenção. Interação em Psicologia, Curitiba, v. 7, n. 2, p. 121-128, 2003.

IMPERATORI, Giceli; LOPES, Marta Julia Marques. Estratégias de intervenção na morbidade por causas externas: como atuam agentes comunitários de saúde? Saúde e Sociedade, São Paulo, v. 18, n. 1, p. 83-94, mar. 2009.

MASCARENHAS, Márcio Dênis Medeiros et al. Epidemiologia das causas externas no Brasil: mortalidade por acidentes e violências no período de 2000 a 2009. In: BRASIL. Saúde Brasil 2010: uma análise da situação de saúde e de evidências selecionadas de impacto de ações de vigilância em saúde. Brasília, DF: Ministério da Saúde, 2011. cap. 10.

MINAYO, Maria Cecília de Souza. O desafio do conhecimento: pesquisa qualitativa em saúde. 8. ed. São Paulo: Hucitec, 2008.

MULLER, Eliane Fransieli. A violência intrafamiliar contra o idoso: um estudo no contexto do Ciaprevi. 2008. 109 p. Monografia (Graduação em Serviço Social) - Universidade Federal de Santa Catarina, Florianópolis, 2008.

NATIONAL CENTER ON ELDER ABUSE - NCEA. Protecting America's senior: the Elder Abuse Prevention Interventions Program. Disponível em: <http://ncea.aoa.gov/About/ News/docs/ElderAbusePreventionGrants2012.pdf>. Acesso em: 11 maio 2013 
NOGUEIRA, Caroline Furtado; FREITAS, Maria Célia de; ALMEIDA, Paulo César de. Violência contra idosos no município de Fortaleza, CE: uma análise documental. Revista Brasileira de Geriatria e Gerontologia, Rio de Janeiro, v. 14, n. 3, p. 543-554, 2011.

OLIVEIRA, Maria Liz Cunha et al. Características dos idosos vítimas de violência doméstica no Distrito Federal. Revista Brasileira de Geriatria e Gerontologia, Rio de Janeiro, v. 15, n. 3, p. 555-566, jul./set. 2012.

ORGANIZAÇÃO MUNDIAL DA SAÚDE (OMS). Relatório Mundial sobre Violência e Saúde. Genebra: OMS, 2002.

SANCHES, Ana Paula R. Amadio et al. Violência contra idosos: uma questão nova? Saúde e Sociedade, São Paulo, v. 17, n. 3, p. 90-100, 2008.

SCARANTO, Catarina Antunes Alves et al. Percepção dos agentes comunitários de saúde sobre a violência doméstica contra a mulher em Chapecó-SC, 2005. Psicologia: Ciência e Profissão, Brasília , v. 27, n. 4 , p. 694-705, dez. 2007.

SHIMBO, Adriano Yoshio; LABRONICI, Liliana Maria; MANTOVANI, Maria de Fátima. Reconhecimento da violência intrafamiliar contra idosos pela equipe da Estratégia Saúde da Família. Escola Anna Nery Revista de Enfermagem, Rio de Janeiro, v. 15, n. 3, p. 506-510, jul./set. 2011.

WAGENAAR, Deborah Ban et al. Primary care physicians and elder abuse: current attitudes and practices. Journal of the American Osteopathic Association, Chicago, v. 110, n. 12, p. 703-711, Dec. 2010.

WANDERBROOCKE, Ana Claudia; MORE, Carmen. Significados de violência familiar para idosos no contexto da atenção primária. Psicologia: Teoria e Pesquisa, Brasília, v. 28, n. 4, p. 435-442, dez. 2012.

Recebido: 23/01/2013

Aceite Final: 05/02/2014 